\title{
El secuestro neoliberal del bienestar. Sobre la factibilidad de la justicia social y las alternativas del futuro
}

\author{
Amaia Inza Bartolomé \\ Departamento de Sociología y Trabajo Social, \\ Escuela Universitaria de Trabajo Social, UPV-EHU \\ <amaia.inza@ehu.es>
}

\begin{abstract}
Ez du egiazko aukera ematen nagusi bilakatu den paradigma neoliberaletik kanpo bestelako Estatu alternatibo bat erabiltzea ingeniaritza sozialeko proiektuak garatzeko. Nagusitutako eredu horrek aukera bakar gisara ulertarazten du nazioarteko konpetentziapean gelditzen direla justizia sozialaren ildoak. Merkataritzaren aurkako tesi batzuek ere prozesu hori atzetik aurrera etortzeko aukera gertatzea moteldu dute. Artikulu honetan berrikusten dira zenbait ildo, betiere egokitzen ari den gizarte-ongizatearen kontzeptua oinarri hartuz, eta aipatutako joera horiek ikustarazten dira bertan. Gainera, inbertsio sozialaren ingeniaritza sozialeko estrategia berritzailea aurkezten da, etorkizunean gertatuko diren erronkei erantzuteko xedez.
\end{abstract}

\section{HITZ-GAKOAK:}

Estatuaren diseinua, neoliberalismoa, nagusitasuna, gizarte-ongizatea, aukerak.
La utilización de un modelo de Estado alternativo para el diseño de proyectos de ingeniería social alejados del paradigma hegemónico neoliberal no parece una opción verosímil. La fuerza de los argumentos de este último, obliga a entender como única posibilidad un conjunto de directrices que someten el despliegue de los términos de la justicia social a imperativos de competitividad internacional. El proceso de deslegitimación de las tesis desmercantilizadoras ha supuesto también la imposibilidad de reversión de este proceso. Este trabajo repasa las pautas que empujan a una concepción similar del desarrollo del bienestar social en constante ajuste y reducción, trazando las líneas comunes de paradigmas de Estado que dejan ver las tendencias antes señaladas, así como una estrategia novedosa de ingeniería social, como la inversión social, que recoge las inercias anteriores y tiene por objetivo responder a los desafíos que plantearán los nuevos riesgos sociales en el futuro.

Palabras Clave:

diseño de Estado, neoliberalismo, hegemonía, bienestar social, alternativas. 


\section{Introducción}

La crisis económica actual ha dejado patente la imposibilidad de marcar una alternativa definida que haga frente a las reglas económicas de corte liberal que marcan el desarrollo del bienestar. Para entender por qué este proceso no parece tener vuelta atrás, es necesario analizar el papel que el modelo de acumulación imperante ha reservado al Estado. Las diferentes alternativas ideológicas manejaban alrededor de este último sus diseños de ingeniería social, modelos en confrontación que permitían establecer diferencias entre los partidos según el lugar que se le ofrecía al Estado en relación al mercado. Se proyectaba así un imaginario social que definía posiciones en un continuum ideológico, el cual hacía posible la percepción de las opciones de derecha e izquierda, conservadora y progresista, o cualquier diferenciación dicotómica que funcionara como referente para la elaboración de propuestas ante un antagonista definido, aunque fuera en el terreno especulativo.

La lucha por la reificación de imaginarios en pos de derechos sociales permitió concebir un bienestar social basado en la igualdad y en la nivelación de las diferencias. Las tensiones actuales llevan, sin embargo, por el camino contrario, en una marejada que parece ser irreversible. La razón principal es que el proyecto hegemónico neoliberal ha maniatado cualquier diseño de Estado, haciendo que las alternativas se plieguen a sus exigencias y despreciando por absurdas aquellas que no reconozcan los logros de sus preceptos.

Los paradigmas de Estado teorizados las últimas décadas recogen los triunfos del discurso neoliberal y ofrecen una perspectiva más amable de las pautas de desarrollo de lo social, necesaria para ganar en legitimidad en unas sociedades que aún consideran que las conquistas en nombre de la igualdad deberían ser inamovibles. A partir de aquí, los términos de la competitividad económica y la tendencia a la minimización del Estado en cuanto al bienestar marcan los paradigmas de referencia, sin visos de una alternativa en confrontación.

Este trabajo describirá cuáles han sido los hitos más importantes en la imbricación entre los criterios neoliberales y los términos del desarrollo del bienestar, planteando las alternativas de despliegue de este último dentro de los paradigmas más destacados en los últimos años. Se recogerán también los planteamientos de la estrategia de la inversión social que pretende hacer frente a los desafíos que en el futuro plantearán los nuevos riesgos sociales.

\section{El proceso de difuminación del Estado de bienestar}

Durante las últimas décadas, el Estado ha ido perdiendo poder de coordinación jerárquico y, a la vez, se ha ido debilitando su función protectora. Se ha apeado así de la dinámica desmercantilizadora, esto es, del proceso en continua expansión por el cual se protegía a la ciudadanía de los riesgos derivados del mercado, para fortalecer las tendencias que externalizan la responsabilidad por el bienestar, implicando determinantemente a la ciudadanía en el esfuerzo por el logro de un estándar mínimo.

El Estado, convertido en actor protagonista en la carrera por la competitividad económica, se postra ante la lógica liberal de acumulación y revierte el camino de la construcción de los términos de justicia social conquistada por las sociedades europeas gracias al empuje del entramado del Estado de bienestar keynesiano. Pueden diferenciarse dos trayectorias paralelas que terminaron con la idoneidad de este último. Por un lado, su falta de dinamismo para adaptarse al proceso acumulativo de una economía en constante cambio; y por otro, la eficiente labor de las elaboraciones ideológicas que defendían su obsolescencia ${ }^{1}$.

\subsection{La insostenibilidad del Estado de bienestar keynesiano}

Tras la segunda posguerra mundial, la estrategia keynesiana incide en la demanda mediante ajustes en la política fiscal, en el nivel de gasto público e impositivo. Buscaba con ello equilibrar las injusticias de la economía de mercado e intentaba erradicar la pobreza y reducir la desigualdad social, promoviendo a la vez el crecimiento y manteniendo el pleno empleo (Heywood, 1997: 95). Las acciones políticas estatales eran capaces de aunar crecimiento económico y justicia social, ofreciendo protección frente a los riesgos comunes generados por las fuerzas del mercado. Ello era fuente de legitimidad en un periodo en la que la socialdemocracia hizo concordar su doctrina con la posición hegemónica en Europa.

Esta época de consenso en torno a valores que decididamente ensanchaban los ámbitos de las políticas sociales logró que este mismo factor fuera el que estabilizara el sistema económico. Incentivando la demanda, reactivaba la producción y el consumo, y por ende, el bienestar. Sus dos grandes objetivos eran el crecimiento económico y la realización de los derechos sociales.

Pero las tendencias inflacionistas de finales de los años sesenta, y la inflación y el paro de los años setenta se tornaron inabarcables para las políticas keynesianas basadas en la estabilización de la demanda inducida por el Estado (Merkel, 1994: 20). A partir de los años ochenta, los políticos asumieron como válidas las políticas monetaristas que defendían que la intervención fiscal del Estado no podía estabilizar las economías. La economía estaba en recesión, lo que condujo al colapso de la confianza en la capacidad del Estado para controlar el funciona-

${ }^{1}$ Se deshizo de esta manera la idea de Estado de bienestar como "espina dorsal de la organización de una civilización que subordinaba así la economía a valores humanos metaeconómicos” (Pfaller et al., 1993). 
miento de la economía mixta. Además, como aclara Mishra (1992), se sostenía que la idea de que podría utilizarse la actividad social planificada bajo los auspicios del Estado para hacer frente de forma efectiva a los problemas sociales se había mostrado poco realista; la política social no podía ser racional, la ingeniería social selectiva tenía efectos no previstos que creaban nuevos problemas.

Así, se replantea la titularidad por el suministro de bienestar bajo una constante tendencia a reducir sus ámbitos de actuación. David Held (1989: 125) recoge las perspectivas de los "teóricos de la sobrecarga del Estado" y los "teóricos de la crisis de legitimación” sobre la necesidad de dicho replanteamiento. Coinciden en que el poder del Estado, medido por su habilidad para resolver las demandas y dificultades que tiene que encarar, estaba siendo progresivamente erosionado. El Estado era cada vez más ineficaz (según los teóricos de la sobrecarga) o escaso en racionalidad (según los teóricos de la crisis de legitimación).

\subsection{La globalización y las exigencias del sistema de acumulación}

Tras la Segunda Guerra Mundial, mediante las negociaciones del el Acuerdo General sobre Aranceles Aduaneros y Comercio (GATT), se establecieron las condiciones para la apertura de los mercados, para eliminar las barreras al comercio. Más adelante, en los años setenta, los países y organismos con poder económico impulsaron una estrategia consensuada, apoyada en la democracia liberal y en las políticas macroeconómicas encaminadas a la baja inflación, los presupuestos equilibrados, la supresión de barreras comerciales y los controles de divisas, la máxima libertad para el capital, la regulación mínima de los mercados de trabajo, la privatización y a un Estado de bienestar dinámico y versátil (Held, 200ob: 98).

Según el análisis de Cerny (1999a: 10-11), tres son los factores económicos interrelacionados que caracterizan el proceso de globalización: la internacionalización de los mercados, las técnicas de producción posfordistas, y el desarrollo de nuevas tecnologías de información y comunicación. Los mercados globalizados son mercados en los que los productos son sustituibles y se puede comerciar con ellos en una extensa región. Además, el capital es móvil y se moverá a sitios donde los beneficios sean más altos y seguros. Por otro lado, las técnicas de producción posfordistas son mucho más flexibles y pueden ser ajustadas a una serie de diferentes condiciones estructurales de mercado al mismo tiempo. En cuanto al desarrollo de nuevas tecnologías de información y comunicación, están transformando los sectores industriales desde dentro y trasladando el peso de las actividades económicas desde la manufactura a los servicios.

Dentro de las nuevas características de la economía política en los países avanzados, nos encontramos, en opinión de Beck (1999), con que la sociedad de pleno empleo ha tocado su techo desde el punto de vista tecnológico y productivo, porque, por primera vez en la historia, la tasa de paro no debe verse como producto de crisis económica cíclicas, sino como resultado de los éxitos del capitalismo tecnológicamente avanzado. La tendencia es hacia la flexibilidad, entendida como la posibilidad de que los empresarios puedan despedir más fácilmente a sus trabajadores, que los contratos sean de corta duración y fácilmente rescindibles y que el Estado traspase los riesgos, cada vez menos calculables, a los individuos. Todo ello conforma lo que este autor ha denominado como "fin de la sociedad laboral", aquella cuyo eje era la articulación entre el trabajo y ciudadanía, y su reemplazo por la sociedad del riesgo en la que la inseguridad y la precariedad laboral son predominantes.

Pero para comprender cuáles son las nuevas reglas del juego, ha de subrayarse la importancia que la globalización ha tenido en la transformación del carácter y las perspectivas de la comunidad política democrática. Como subraya David Held (2000a: 6), el locus del poder político efectivo ha dejado de ser el Gobierno nacional: el poder es compartido y pactado por fuerzas y entidades diversas en los niveles nacional, regional e internacional. Además, Held afirma que la idea de comunidad de destino en sentido político no puede ya situarse coherentemente dentro de los límites de una sola nación-Estado.

En este sentido, Bauman afirma que mientras que los agentes tradicionales ya no son capaces de llevar a cabo ninguna acción eficaz, los agentes verdaderamente poderosos y con recursos se han ocultado y operan fuera del alcance de todos los medios tradicionales de acción política, especialmente fuera del alcance del proceso de negociación y control democrático centrado en el ágora. Su ausencia de ella los favorece. La regulación normativa no les ofrece ninguna ventaja y, por lo tanto, no necesitan del ágora (Bauman, 2001: 108)². En opinión de Beck (1998: 16), el poder de las empresas multinacionales también supone una politización, porque desempeña un papel clave en la configuración de la economía y de la sociedad en su conjunto.

Los mercados internacionales de capital imponen una estricta disciplina sobre los Gobiernos, reaccionando con gran rapidez ante cualquier decisión política, erigiéndose en poder fiscalizador de los Estados (Dehesa, 2000: 118; Held, 2000a: 5). Su carácter 'líquido' hace que tengan una gran facilidad para entrar y salir de las comunidades políticas, premiando a los Gobiernos que consiguen una buena credibilidad internacional con mayores y más baratos flujos de capital y de inversión, y castigando a aquellos que toman medidas poco ortodoxas. De

${ }^{2}$ Hay una red crecientemente densa de Gobiernos transnacionales de interés privado que están en proceso de cristalización. Incluyen tanto instituciones formales como informales que no son responsables democráticamente, generan productos que reflejan intereses privados más que públicos, y operan sin necesidad del Estado o una autoridad delegada (Cerny, 1999a: 18). 
esta manera, el mercado se ha convertido en el nuevo Gran Inquisidor (Culpitt, 1992: 46): constituye una fuente de inestabilidad sin precedentes, de manera que la actuación de los Gobiernos se encuentra constantemente en la cuerda floja, a la espera de qué medidas tomarán los mercados ante su situación. A partir de aquí, el Estado, que había ido acumulando responsabilidades, haciéndose más responsable de todo y creando un orden desde arriba, ha pasado a una posición defensiva y ya no organiza la sociedad, sino que la defiende (Vallespín, 2000: 144)33. Por otro lado, más que una acción correctora, tendrá una acción amortiguadora (Mishra, 1992: 47).

El debate se centrará a partir de ahora en las restricciones a la capacidad de intervención utilizada a por el Estado-nación para llevar a cabo políticas sociales que lo legitimen. Ello en un contexto de déficit de legitimación de los procesos de toma de decisiones, así como de una incapacidad creciente de realizar sus funciones organizativas y de gobierno (Habermas, 2001: 5,6). También supone una revaluación de la concepción de los bienes públicos o colectivos en un mundo globalizado, ya que muchos de los que eran considerados bienes colectivos en la segunda revolución industrial, no son ya controlables por el Estado, porque se han convertido en transnacionales en su estructura o se han constituido en bienes privados en el amplio mercado mundial; en definitiva, lo que está en el centro del debate político es qué debería ser tratado como público y qué no (Cerny, 1999b). En este sentido, Pierson (1998b: 539) opina que es probable que la reforma exitosa del Estado de bienestar se base en el compromiso y que tome la forma de un contrato social reestructurado y modernizado.

\section{Premisas básicas en la reestructuración del Estado de bienestar}

\subsection{La influencia del neoliberalismo en el cambio de perspectiva}

La reestructuración ideológica en torno al papel del Estado en la economía sufrió un impulso definitivo debido al incremento de los flujos globalizadores, los cuales suponen un cambio en la relación establecida entre el derecho, la política y la economía de mercado en las democracias surgidas de la segunda posguerra mundial. Según el análisis de Baylos (1999a: 22), en estas últimas se procedía a una cierta conciliación entre la lógica de la explotación y del beneficio propia del sistema capitalista, y la lógica democrática de la igualdad expresada en la nivelación social. Tal compromiso implicaba la primacía de la política sobre la economía, es decir, que el principio político-democrático orientaba la regulación del mercado y la obtención del beneficio. El proceso globalizador ha dado por finalizada, por tanto, esta

\footnotetext{
3 Nos encontramos ante una quiebra entre el mundo político y el económico, en la que este último vacía de sentido al primero, hiriendo las formas en las que se construyen tanto el vínculo social como los cimientos del contrato social (Vallespín, 2000: 144).
}

visión. No en vano, dentro de la estrategia neoliberal que la globalización trae aparejada, está el intento de denostar todo lo público y ampliar el ámbito del beneficio privado a través de la consecución de un cambio cultural que lleve a percibir negativamente las prestaciones y servicios públicos, la regulación estatal y la participación del sector público en la economía, identificando, sin embargo, las privatizaciones y la extensión del mercado como elementos progresistas (VV.AA., 1993: 8) ${ }^{4}$.

Algo que se ha de tener muy en cuenta en el desarrollo de los acontecimientos es que el neoliberalismo no espera la legitimación normativa de su Estado ideal mediante la persecución de valores como la justicia social, ya que su manera de hacerlo es mediante la prosperidad material; además, para los neoliberales no hay objetivos colectivos que puedan ser deseados y, por lo tanto, no deberían ser objetivos de las políticas del Estado (Plant, 2004: 34-35). Por añadidura, hay un creciente consenso entre los políticos acerca de que, hasta cierto punto, las dimensiones del neoliberalismo son parte de un paquete coherente de reformas que son vistas como necesarias a la luz de la creciente interdependencia y de la realidades globales (Cerny, 2004).

Dentro del mismo proceso, se ha impuesto una retórica política basada en un liberalismo antipolítico que ve con naturalidad la existencia de desigualdades sociales y que pugna por reducir el poder político a la mera protección del sistema mundial (Hirst y Thompson, 1996: 46). El discurso neoliberal determina la reflexión sobre la cuestión social, pues bajo esta perspectiva, las políticas sociales no pueden resolver los problemas sociales, ya que éstos no son de orden social, sino personal. Mantienen que, como la dinámica social no se ve afectada por los procesos de desviación, es solamente un problema de ajuste y socialización (Álvarez-Uría, 1998: 27-28).

Se rechaza de plano, por lo tanto, el despliegue del ámbito estatal con respecto a la protección del bienestar, ya que el aumento del gasto público es causa del deficiente funcionamiento del Estado. Las características del desarrollo de la economía mundial mencionadas anteriormente hacen que la interacción entre los Gobiernos y los móviles negocios y finanzas supongan un 'dilema del prisionero' para los Estados, que lleva a un guerra en la que las transferencias de bienestar, los servicios sociales y los impuestos que los hacen posibles son reducidos al mínimo común denominador (Swank, 2001: 204). Así, los constreñimientos que se ciernen sobre el Estado de bienestar reducen el espacio político de maniobra, es decir, el conjunto factible de opciones realistas (Merkel, 2001: 14). Las consecuencias más evidentes se plasman en los cambios en la concepción del Estado como suministrador de bienestar, en la titularidad de los

${ }_{4}$ Así, el Estado va tomando las características de un guardián: un Estado con funciones mínimas, aunque importantes, relacionadas con el mantenimiento de la ley, el orden público, una moneda sólida y la vigilancia del cumplimiento de los contratos (Gamble, 2003: 67). 
receptores de los servicios sociales y en la relación triangular Estado-mercado-sociedad civil. En principio, se pone en cuestión un Estado sobre el que pesa toda la responsabilidad en cuanto a la provisión de bienestar, y se contempla la cesión de ésta a la sociedad civil como una opción válida. Es más, el éxito de la acción del Estado pasa necesariamente por una desjerarquización de las relaciones entre Estado y sociedad, rompe con la idea del Estado como coordinador jerárquico, dando paso a uno mucho más fungible, donde la dirección política ha de interactuar necesariamente con la propia autorregulación social (Vallespín, 2000: 134-137).

Además, se cuestiona el papel pasivo del individuo como mero receptor de beneficios sociales, intentando a partir de ahora hacerle copartícipe en la responsabilidad de su bienestar, haciéndole bregar por mantener unos privilegios de los que antes disfrutaba por su mera condición de ciudadano/a. De esta manera, pasan de ser el eje de las preocupaciones del Estado paternalista a estar en el centro de un tira y afloja que pretende la racionalización del Estado de bienestar. Se remercantilizan esferas que se consideraban un paso determinante en el avance hacia la expansión de los derechos de ciudadanía, pasando cada vez más áreas a estar desprotegidas y al albur de las fuerzas del mercado de trabajo.

El debate sobre la naturaleza del Estado de bienestar se centra en dos escenarios. Por un lado, está la tesis de la convergencia del bienestar: los Estados pierden fuerza para hacer elecciones políticas reales; es decir, los Gobiernos se ven forzados a adoptar políticas económicas, fiscales y sociales similares. Esto implica el abandono de las políticas redistributivas de bienestar y su sustitución por la desregulación, la privatización y la residualización, que lleva a cierta forma de convergencia. Por otro lado, está la tesis de race to the bottom (carrera a la baja): sucede mediante la devaluación competitiva de los estándares de protección social para hacer a un país y a sus trabajadores más atractivos a los inversores. También se la conoce como dumping social: supone tanto la erosión de los niveles establecidos de protección social como el desarrollo contenido de la protección y la regulación social. Implica el desplazamiento del coste de la protección social desde el Estado y los empleadores hacia los trabajadores (Yeates, 2001: 23-25).

El camino para el diseño del Estado de bienestar realizable comienza por el reconocimiento de que el Estado desempeñará un papel más pequeño en la protección social. Tal y como predijo Ramesh Mishra hace más de una década, el sector estatal se reducirá en todas partes debido a los factores políticos e ideológicos que han privilegiado la economía de mercado, el individualismo y la competición. Los ciudadanos demandarán del Gobierno seguridad e igualdad, y el Estado de bienestar no podrá en absoluto ser desmantelado, pero no podrá ser sostenido en las bases de universalidad e igualdad. Esto tiene como consecuencia inmediata que los programas sociales tendrán cada vez menos importancia en el gasto. En definitiva, el tamaño y los objetivos de los programas del Estado serán reducidos en todas partes, y el bienestar se alejará de su base en la ciudadanía social (Mishra, 1996: 317).

En cuanto a la categorización de distribución de prestaciones, en opinión de Picó (1992: 302) lo que subyace es la vieja distinción igualdad frente a meritocracia, es decir, el peso relativo que se ha de asignar a las necesidades y los méritos en la distribución del bienestar. Así pues, el futuro del Estado de bienestar podría girar en torno a: la delimitación de un nivel básico de prestaciones atendidas por el Estado y aplicadas a toda la población, entendidas como derechos de ciudadanía; una segunda franja de prestaciones estaría garantizada y regulada por el Estado, pero financiada con criterios selectivos en referencia a la renta, y producidos de forma mixta Estado-mercado; una tercera franja de prestaciones serían incentivadas por el Estado, pero producidas, financiadas y gestadas de forma casi exclusivamente mercantil.

El desafío para los Estados vistos a través del discurso contemporáneo de la globalización, en palabras de Cerny (1997: 262), será hacer frente a las limitaciones que se ciernen sobre ellos, intentando combinar la austeridad con una red básica de bienestar que pueda mantener el consenso suficiente, siempre que al mismo tiempo promueva la reforma estructural en los niveles mesoeconómicos y macroeconómicos para mejorar la competitividad internacional.

\subsection{El cuestionamiento de los derechos sociales}

Tanto la lógica económica, que tiene como contrapartida la degradación de lo social y la búsqueda de la privatización del bienestar (Mishra, 1996: 317), como los cambios ideológicos sobre la noción de seguridad y bienestar en las sociedades avanzadas que llevan a cuestionar la funcionalidad, la eficacia e incluso la equidad de los criterios de universalidad basados en el principio de la ciudadanía social, favorecen la extensión de los apoyos hacia un sistema de bienestar residual, individualista y fundado en la demostración de la necesidad (Benedicto y Reinares, 1992: 21; Swank, 2001: 204).

Se socava también el principio de universalidad, ya que con la residualización del Estado de bienestar se pone en jaque la concepción de Marshall de los derechos sociales como atributos de la ciudadanía (Marshall y Bottomore, 1998). En palabras de Pierson (1998a: 778), el cambio de defender soluciones colectivas para las necesidades sociales, a preferir satisfacer demandas de bienestar individuales lleva al replanteamiento del Estado de bienestar de un modelo universalista basado en el derecho a uno residual basado en un sistema de provisión pública regido por las necesidades. Se trataría de un modelo que sólo daría plena protección a los más pobres, mientras que los más acomodados serían privados selectivamente de algunos beneficios o pagarían una cuota por los 
servicios (Picó, 1992: 301). Esta selectividad, en contraste con los derechos sociales universales, conecta los servicios con los recursos, promueve el acceso a prestaciones de bienestar por comprobación de medios (means-testing) y provoca la estigmatización de los receptores (Procacci, 2001: 49, 56).

Siguiendo con la lógica anteriormente señalada, Baylos destaca el fenómeno de la pérdida de la noción de patrimonio político de los derechos sociales como derechos ciudadanos, y la sustitución paulatina del título sobre el que otorga la protección social. Esta última no se otorga a un sujeto político, el/la ciudadano/a, que tiene derecho a una prestación social, sino que el/la beneficiario/a de ésta se presenta como un/a usuario/a de un servicio que tiene interés en que le sea prestado en las mejores condiciones. Así, si las prestaciones sociales se consumen, quiere decir que están integradas en un mercado de bienes y servicios, único lugar desde el que se puede eficientemente asignar recursos a las personas. Es un proceso de despolitización de la relación de Seguridad Social que va en paralelo a la tendencia de privatización en el discurso neoliberal (Baylos, 1999b: 31). Simultáneamente, la seguridad del empleo y las condiciones de trabajo decente dejan de ser derechos de ciudadanía y se convierte en algo que los empleadores eligen extender a ciertos tipos de trabajadores/as, dependiendo sólo de consideraciones de mercado (Crouch et al., 2001: 9, 11).

El reflejo de las tendencias anteriormente descritas puede verse en diferentes paradigmas de Estado que han sido teorizados estos últimos años.

\section{Los paradigmas y su función descriptiva. Mercantilización, nuevos riesgos sociales e inversión social}

La noción de paradigma de políticas incluye ideas sobre los objetivos de las políticas, la identificación de elementos que pueden ser problemáticos en relación a esos objetivos, una explicación de por qué los problemas aparecen, diferentes soluciones a los problemas identificados y las definiciones del papel apropiado del Gobierno y de otros actores (Hall, 1993: 279). En general, la transición a un nuevo paradigma busca su legitimidad aludiendo a una manera de lograr la seguridad, entendida como la consecución (por parte de la ciudadanía) y el suministro (por parte del Estado) de los medios para desenvolverse en el mercado de trabajo. En este sentido, la presión sobre la ciudadanía es cada vez mayor, y el ámbito de actuación del Estado, cada vez más reducido.

Los paradigmas, pues, nos ayudan a entender el papel asignado al Estado en relación a las nuevas circunstancias. Si bien algunos paradigmas subrayan la tendencia a la mercantilización y el rol de la política social como obstáculo al proceso acumulativo, la estrategia de la inversión social erige sobre el ya reducido papel del Estado en el bienestar la posibi- lidad de utilizar la política social como un elemento productivo fundamental para el desarrollo económico. Ello en un contexto en el cual la diversificación y la eficiencia de los instrumentos de los que dispone el Estado han de incrementarse de cara al futuro, ya que a los viejos riesgos y las dificultades que plantean debemos sumarles los nuevos riesgos sociales de las sociedades posindustriales.

\subsection{La mercantilización como idea rectora}

Los paradigmas que tienen por eje la mercantilización destacan que la lógica económica relega la esfera de lo social a un segundo plano y la consecución de derechos sociales cada vez estará más circunscrita a la posición en el mercado de trabajo. Esta tendencia se refleja en las teorizaciones que se desarrollarán a continuación.

Las características principales del "régimen postnacional schumpeteriano de workfare" (Jessop, 2008) vienen definidas por el hecho de que se subordina la política social a las necesidades de flexibilidad del mercado de trabajo y, en general, a la competición internacional, y que promueve la innovación organizacional y de mercado en la economía, con el objetivo de fortalecer, en lo posible, la competitividad estructural de las economías nacionales, interviniendo en el lado de la oferta. La educación y la preparación tienen una importancia central en la estrategia del workfare, dentro de la cual se intenta rehacer los modelos de personas que deben servir como ejemplo de la innovación, de primacía del conocimiento, de economía flexible, empresarial y autónoma. El workfare reducirá el gasto social con respecto a aquellos que no son potencialmente miembros activos del mercado de trabajo o ya lo han abandonado, y también si el gasto se circunscribe a demandas de ingeniería social. También se reducirá en lo que respecta a su función como compensador del trabajador por los riesgos referentes al comercio internacional.

Por otro lado, según el análisis de Philip Cerny (2000), ha emergido el "Estado de competición”, que persigue incrementar la mercantilización con el objetivo de hacer que las actividades económicas de los países sean más competitivas internacionalmente, promoviendo dicha mercantilización en términos económicos e ideológicos. Los puntos más importantes de este proceso incluyen intentos de reducir el gasto gubernamental y la desregulación de las actividades económicas, especialmente de los mercados financieros. Así, los aparatos del Estado se han convertido en residuales en lo que respecta a la consecución de algunas formas de bien común, lo cual dificulta a sus instituciones personificar la solidaridad comunitaria, que propició al Estado-nación moderno su profunda legitimación, poder institucionalizado e implantación social. El gasto de bienestar sólo puede estar justificado como estabilizador del sistema económico y como instrumento que permite la maximización de opciones de mercado orientadas al crecimiento. 
Según el análisis de Bobbit (2002), el orden constitucional del Estado-nación estaba siendo asediado en todas partes, emergiendo un nuevo modelo que denomina "Estado de mercado". Esta transformación supone un cambio en la visión sobre la básica razón de ser del Estado, del propósito legitimador que lo sostiene, y establece los nuevos términos en torno a los que giran los desafíos estratégicos a los que se enfrenta. Mientras que el anterior modelo de Estado, con su gratuita educación pública, sus derechos universales y sus políticas de seguridad social prometía garantizar el bienestar de la nación, el Estado de mercado promete maximizar las oportunidades de la gente, tiende a privatizar muchas actividades del Estado, y evalúa su éxito o fracaso económico por la habilidad para asegurar más o mejor bienes y servicios. Bobbit ve al Estado como proveedor o redistribuidor mínimo. El hecho de que sólo se pueda incrementar el nivel de bienestar de un país con el crecimiento del déficit obliga al abandono progresivo del objetivo del Gobierno de mejorar el bienestar de los ciudadanos. Es decir, tendría que cambiar un elemento crucial en la base de su legitimación como Estado.

Por otro lado, Gilbert (2002) menciona que el cambio es desde políticas contextualizadas en una aproximación universal de beneficios suministrados públicamente, diseñados para proteger el trabajo contra las vicisitudes del mercado y sostenidas firmemente como derechos sociales, a políticas encuadradas en una aproximación selectiva para el suministro de provisiones diseñadas para promover la participación de la fuerza de trabajo y la responsabilidad individual, resumida bajo la máxima ‘apoyo público para la responsabilidad privada'. 0 por decirlo, más claramente, un cambio del tipo ideal de bienestar socialdemócrata a una versión orientada al mercado, que se puede identificar con la aproximación angloamericana que este autor llama "Estado capacitador”. Bajo esta perspectiva, el Estado de bienestar tal y como lo conocemos está siendo suplantado en varias naciones por nuevas medidas bajo las cuales las provisiones sociales son transferidas mediante incentivos al trabajo, beneficios impositivos y otras medidas diseñadas para ofrecer apoyo público a la responsabilidad privada. Las políticas inspiradas por la competición, la oportunidad, la productividad y el hecho de sopesar racionalmente los costos y beneficios mensurables llevan la provisión de lo social y la protección al terreno de lo comercial.

En opinión de Torfing (1999), el cambio de las provisiones pasivas a los programas de activación del mercado es visto como un paso desde los derechos incondicionales combinados con casi ninguna obligación, al condicionamiento de los derechos sociales relacionados con las obligaciones. En concreto, las políticas de workfare pueden ser caracterizadas por un incremento de los elementos coercitivos y de imposición con respecto a la participación en el mercado de trabajo, lo cual puede suponer recortes en prestaciones sociales, la mayor exigencia en los criterios a la hora de elegir a los beneficiarios, y el condicionamiento de la transferencia en los pagos (Dingledey, 2005).
Según las ideas anteriormente mencionadas, los Gobiernos deberían proveer de unas condiciones de ciudadanía similares, pasando de la agenda de derechos a moverse a una de capacitaciones. En un contexto en el que la ciudadanía tiene que hacer frente a ciertas responsabilidades, el reparto de tareas es el siguiente: el Estado debe proveer al individuo de instrumentos para defenderse en un mundo globalizado, y un Estado de bienestar que no puede seguir cumpliendo las funciones que antes desempeñaba debe crear la igualdad de oportunidades para que el sistema funcione y para lograr la legitimidad necesaria mediante cierto logro de justicia social amoldado a 'la realidad'; por otro lado, el individuo responsable no puede hacer valer sus derechos si no cumple con sus obligaciones.

\subsection{Los nuevos riesgos sociales y la sociedad posindustrial}

En otro orden de cosas, ya desde los años sesenta nos encontramos con el fin del industrialismo, que trae cambios en la economía, la tecnología y los sistemas de trabajo, y da lugar a la sociedad posindustrial (Bell, 1976). Este paso supone cambios muy importantes en el entramado institucional. Tal y como afirma Bell, el principio sobre el que se moverá la sociedad posindustrial es la centralidad del conocimiento teórico y del conocimiento técnico como fuente de innovación y de elaboración de políticas. El ámbito estrella es la capacidad de los técnicos y los teóricos en economía y en informatización de la comunicación.

La mayoría de los elementos que bajo el keynesianismo establecían certidumbres manejables se deshicieron con este cambio. En una sociedad posindustrial típica, las tasas de crecimiento económico son más bajas y más inciertas. Dentro de cada país, el envejecimiento de la población, el descenso de nacimientos, los cambios en los roles de género, la individualización, el cambio a una economía de servicio y el incremento de la migración suponen nuevos desafíos endógenos para el Estado de bienestar.

Debido a los cambios tecnológicos, el empleo estable en masa en el sector de la manufactura ya no es posible, y esto repercute en la seguridad en el empleo de los trabajadores semicualificados o sin cualificación, y en la estructura de clase y los intereses políticos asociados a ella (Taylor-Gooby, 2004). El movimiento hacia esta sociedad basada en el conocimiento es probable que exacerbe los riesgos de la exclusión social. Esto afecta a los grupos con menos capacitación, en particular aquellos que no tienen, o no han podido adquirir, las habilidades para triunfar en este tipo de economía. Por añadidura, hay un declive de los empleos bien pagados y un incremento de los empleos precarios. Las tendencias hacia las desigualdades de ingresos y la inestabilidad del mercado de trabajo suponen que los ingresos logrados por el empleo ya no sean suficientes para asegurar una existencia sin pobreza, especialmente para las fami- 
lias con niños. Estas nuevas contingencias no están bien cubiertas por los Estados de bienestar heredados (Bonoli, 2006; Jenson y Saint-Martin, 2006).

Por esa razón, tal y como explica Hemerijck (2011), la razón fundamental por la que los Estados de bienestar deban ser hoy activos y proveer servicios sociales capacitadores es debido a la cambiante lógica aseguradora tras los años ochenta. Cuando el riesgo de desempleo industrial era aún cíclico, tenía sentido administrar seguros colectivos durante periodos determinados. Pero cuando el desempleo se convierte en estructural, causado por giros radicales en la demanda y la oferta de empleo, una competición internacional intensificada, el cambio tecnológico, la feminización de la fuerza laboral, las transformaciones en la familia, y las preferencias sociales y económicas para unas relaciones de empleo más flexibles, el tradicional seguro por desempleo ya no funciona como una reserva de ingresos amortiguadora entre empleos. Por otro lado, éstos deben ser complementados con servicios públicos capacitadores, adaptados a necesidades sociales particulares causadas por contingencias en el curso de la vida. Ya que es difícil asegurar los nuevos riesgos sociales privada o colectivamente, y como los servicios sociales capacitadores no son suministrados por mercados privados, se convierte en algo obligatorio para las políticas públicas proveer de una protección efectiva contra estos nuevos riesgos sociales.

Las políticas de bienestar acerca de los nuevos riesgos se refieren a la movilización de la población para enlazar la competitividad y a expandir las oportunidades y un comportamiento distinto con respecto a las responsabilidades. Se trata de que la reforma pueda hacer frente a los nuevos riesgos de la sociedad contemporánea, para hacer sostenibles los sistemas de bienestar y hacerlos productivos, en el sentido de que deberían promover y apoyar el empleo y el crecimiento económico. Central a la modernización de los sistemas de bienestar es la idea de que la política social debería ayudar a preparar a la población a prevenir ciertos riesgos sociales y económicos asociados a unas condiciones de empleo y unos modelos de familia cambiantes, y minimizar la transmisión de pobreza intergeneracional, más que para reparar, a través de esquemas de mantenimiento de ingresos pasivos, después de que el riesgo haya ocurrido (Morel et al., 2012: 9).

Es destacable que, ante la necesaria reelaboración, Esping-Andersen (2002) señala que la alternativa a un mercado de trabajo de remuneraciones bajas no es otra que el desempleo masivo; por lo tanto, si no se pueden evitar los salarios bajos ni el empleo precario, hay que intentar suavizar los efectos de aquél a corto plazo, pero advierte que esta situación se convertirá en una trampa si se prolonga. El elemento central en la redefinición del bienestar no es que en un determinado momento de sus vidas una serie de personas estén en condiciones precarias, ya que probablemente la sociedad no podrá prevenir que esto ocurra, sino que se trata de evitar que esto sea per- manente, que atrape a los ciudadanos de manera que todas sus oportunidades puedan verse afectadas. En breve, el núcleo principal de los derechos sociales debería ser redefinido como garantía efectiva contra esas trampas, es decir, como una serie de garantías de oportunidades de vida.

\subsection{La estrategia de la inversión social como opción de futuro}

Mientras que los paradigmas basados en la mercantilización marcaban un escenario negativo de disminución y constreñimiento, existen perspectivas que reservan al Estado una función proactiva, capacitadora y preventiva que intente enlazar las circunstancias de la globalización y las tensiones propias de la sociedad posindustrial a las que debe hacer frente, subrayando el potencial productivo de la política social. La perspectiva de la inversión social no es una idea nueva 5 , ya que emergió en los años noventa con la doble ambición de: a) modernizar el Estado de bienestar para que pudiera hacer frente a los nuevos riesgos sociales y a las necesidades de las sociedades contemporáneas; y b) asegurar la sostenibilidad financiera y política del Estado de bienestar, mientras mantiene una economía basada en el conocimiento. Intenta reconciliar los objetivos sociales y económicos, alejando la idea de que el gasto social es una rémora para el sistema. Pretende enfocar las políticas públicas para que preparen a los individuos, las familias y las sociedades para que se adapten a variadas transformaciones, más que simplemente generar respuestas cuyo propósito sea reparar, a través de beneficios pasivos, cualquier daño causado por los fallos del mercado, la mala suerte, la mala salud o las 'inadecuaciones' políticas que prevalezcan (Vandenbroucke et al., 2011). Es decir, hace una decidida defensa del gasto social como punto de apoyo para el crecimiento, pero insiste en que debería ser reencauzado desde las políticas sociales pasivas a las activas. En esta perspectiva, la sostenibilidad económica del Estado de bienestar está anclada en el número y la productividad de los futuros contribuyentes; por ello, la política social debería contribuir a movilizar activamente el potencial productivo de los/as ciudadanos/as, con el objetivo de mitigar los nuevos riesgos sociales.

Esta aproximación descansa en políticas que invierten en el desarrollo de capital humano -cuidado y educación de la infancia, educación y formación durante toda la vida - y que ayudan a hacer un uso eficiente de dicho capital -a través de políticas activas de empleo, formas específicas de regulación del mercado de trabajo e instituciones de protección social que promueven una seguridad flexible-, mientras se fomenta una mayor inclusión social, facilitando el acceso al mercado de trabajo. El Estado deberá proveer transferencias para compensar

5 Uno de los primeros teóricos del Estado social inversor fue Anthony Giddens, dentro de su propuesta de una Tercera Vía para la renovación de la socialdemocracia (Giddens, 1999). 
cuando los ingresos de mercado no sean lo suficientemente altos para cubrir las necesidades de las familias, y debe estar atento a los que han sido excluidos e incidir en la promoción de la creación de trabajos de calidad (Morel et al., 2012; Jenson, 2007).

Hemerijck (2011) cree importante subrayar que no hay contradicción entre esfuerzos explícitos de bienestar, es decir, que la inversión social no es sustituta de la protección social. Una adecuada protección de ingresos mínima es una precondición para una estrategia de inversión social efectiva. Destacan Perkins et al. (2004) que existe un consenso, dentro de esta estrategia, en que su principal objetivo es el desarrollo de una sociedad activa en la cual se logre la inclusión social. Ayudar a los más vulnerables y desaventajados y asegurar que no quedan detrás es un tema recurrente en toda la literatura de la inversión social.

\section{Conclusiones}

Cerrando el círculo de la inevitabilidad de las opciones descritas en este artículo, vemos cómo, a pesar de que la crisis ha supuesto un fisura incomensurable en el modo de acumulación capitalista imperante, el discurso neoliberal ha conseguido convertir en realidad aquello que se proclamaba con el acrónimo T.I.N.A. (There Is No Altenative) de los años ochenta, gracias a haber maniatado el recurso de un modelo alternativo de Estado. Ello es así porque los términos justificativos han sido suficientes para que no haya habido una crisis de legitimación en el proceso. Los sacrificios en aras de la competitividad, se repite, son necesarios.

La propia crisis del Estado de bienestar keynesiano, así como la ofensiva ideológica que lo deslegitimaba, hacen improbable una vuelta atrás y que los ámbitos que se consideraba que debían protegerse estén en constante revisión. A ello se le debe sumar la constante petición de austeridad requerida tras la crisis financiera y económica actual. Si bien el principal argumento fue que el gasto social entorpe- cía los posibles beneficios que se podían conseguir con la dinámica económica de rasgos neoliberales, el triunfo de las tesis de esta última doctrina obliga a que cualquier intervención sobre la esfera social tenga que hacerse bajo sus requerimientos.

El bienestar es definido alrededor de un Estado con atribuciones menguantes, en un constante ajuste a la baja de su ámbito de actuación y en un contexto de condicionamiento de los destinatarios de los derechos sociales, antes protegidos como derechos de ciudadanía. La menor importancia dentro del gasto de aquellos recursos destinados a proteger a los individuos ante las vicisitudes del mercado de trabajo obliga a jerarquizar su distribución, a la vez que se trata de paliar las situaciones más graves de exclusión, a fin de que no rompan la cohesión social. El bienestar parece ser cada vez menos atributo del Estado, para pasar a ser objeto de consumo en el mercado y, cada vez en mayor medida, la responsabilidad para con el propio futuro parece que debe estar en manos de la propia ciudadanía.

Los paradigmas aquí presentados son reflejo de los estrechos márgenes de los que dispone el debate ideológico en cuanto al diseño de Estado. Desaparecen así los grandes debates discursivos entre opciones en oposición sobre los modelos de sociedad justa y, sobre todo, la posibilidad de reflexionar sobre las causas sistémicas que generan las desigualdades. Aun así, un Estado con recursos más débiles se ve obligado a reinventarse para mantener su legitimidad ante el papel preponderante del mercado, sin olvidar el despliegue de la justicia social que le sea posible. Ante aquellos modelos que destacan la mercantilización, donde la política social está subordinada al mercado, aparecen estrategias de inversión que piden una remodelación del Estado para que sea más activo, adaptable y que pueda utilizar la política social como base productiva que contribuya al desarrollo económico. Parece que, ante las circunstancias actuales de crisis, son este tipo de estrategias las que pueden hallar el camino para hacer frente a viejos y nuevos riesgos sociales, y amortiguar las desigualdades sociales. 
ÁLVAREZ-URÍA, F. (1998): “Retórica neoliberal. La gran ofensiva de los científicos sociales contra las políticas sociales en EE.UU.”, Claves de Razón Práctica, vol. 80, págs. 20-28.

BAUMAN, Z. (2001): En busca de la política, Buenos Aires, Fondo de Cultura Económica.

BAYLOS, A. (1999a): “Globalización y derecho del trabajo: realidad y proyecto", Cuadernos de Relaciones Laborales, vol. 15, págs. 20-49 [rhttp://revistas.ucm.es/index.php/CRLA/ article/view/CRLA9999220019A/32488>].

- (1999b): “Estado de bienestar y derechos sociales", en FERNÁNDEZ, T.; y GARCÉS, J. (coords.), Crítica y futuro del Estado de bienestar: reflexiones desde la izquierda, Valencia, Tirant Lo Blanch, págs. 21-34.

BECK, U. (1999): Un nuevo mundo feliz. La precariedad del trabajo en la era de la globalización, col. Estado y Sociedad, Barcelona, Paidós.

- (1998): ¿Qué es la globalización? Falacias del globalismo, respuestas a la globalización, col. Estado y Sociedad, Barcelona, Paidós.

BELL, D. (1976): El advenimiento de la sociedad postindustrial, Madrid, Alianza.

BENEDICTO, J.; REINARES, F. (1992): “Las transformaciones de lo político desde una perspectiva europea", en BENEDICTO, J. y REINARES, F. (eds.), Las transformaciones de lo político, Madrid, Alianza Universidad, págs. 9-34.

BOBBIT, P. (2002): The Shield of Achilles, Londres, Penguin.

BONOLI, (2006): "New social risks and the politics of postindustrial social policies", en ARMINGEON, K.; y BONOLI G. (eds.), The Politics of Postindustrial Welfare States: Adapting Post-war
Social Policies to New Social Risks, Londres, Routledge.

CERNY, P. G. (2004): “Mapping varieties of neoliberalism”, IPEG Papers in Global Political Economy, no 12.

- (2000): "Restructuring the political arena: globalization and the paradoxes of the competition state", en GERMAIN, R. D. (ed.), Globalization and its Critics. Perspectives from Political Economy, Londres, PERC-MacMillan, págs. 117-138.

- (1999a): "Globalization and the erosion of democracy", European Journal of Political Research, vol. 36, ํำ 1, págs. 1-26.

- (1999b): “Reconstructing the political in a globalizing world: States, institutions, actors and governance", en BUELENS, F. (ed.), Globalization and the Nation-state, Cheltenham, Edward Elgar, págs. 89-137.

- (1997): "Paradoxes of the competition state: The dynamics of political globalization", Government and Opposition, vol. 32, no 2, págs. 251-274.

CROUCH, C.; EDER, K.; TAMBINI, D. (2001): “Introduction”, en CROUCH, C., EDER, K.; y TAMBINI, D. (eds.), Citizenship, Markets and the State, Oxford, Oxford University Press, págs.1-49.

CULPIT, I. (1992): Welfare and Citizenship. Beyond the Crisis of the Welfare State?, Londres, Sage.

DE LA DEHESA, G. (2000): Comprender la globalización, Madrid, Alianza.

DINGLEDEY, I. (2005): “Welfare state transformation between workfare and an enabling state: A comparative analysis", TranState Working Papers, n을 21, [〈http://hdl.handle.net/10419/28271)].

ESPING-ANDERSEN, G. (2002): "Towards the good society, once again?", en ESPING-ANDERSEN, G. et al., 
Why We Need a New Welfare State, Oxford, Oxford University Press.

GAMBLE, A. (2003): Política y destino, Madrid, Siglo XXI.

GIDDENS, A. (1999): La tercera vía. La renovación de la socialdemocracia, Madrid, Taurus.

GILBERT, N. (2002): Transformation of the Welfare State. The Silent Surrender of Public Responsibility, Oxford, Oxford University Press.

HABERMAS, J. (2001): "El valle de lágrimas de la globalización”, Claves de Razón Práctica, vol. 109, págs. 4-10.

HALL, P. A. (1993): "Policy paradigms, social learning and the state: The case of economic policymaking in Britain", Comparative Politics, vol. 25, n- 3 , págs. 275-296 [rhttp://chenry.webhost.utexas. edu/core/Course\%2oMaterials/Hall/o.pdfs].

HELD, D. (2000a): “¿Hay que regular la globalización? La reinvención de la política”, Claves de Razón Práctica, vol. 99, págs. 4-11.

- (2000b): “¿Entiende el nuevo laborismo la globalización?”, Leviatán, vol. 79, págs. 95-105.

- (1989): Political Theory and the Modern State, Cambridge, Polity Press.

HEMERIJCK, A. (2011). "Social investment is in jeopardy", en VV.AA., Social Progress in the $21^{\text {st }}$ Century, London, Policy Network; Wiardi Beckman Stichting; y Foundation for European Progressive Studies, págs. 24-29 [<http://www. policy-network.net/publications_download. aspx? $[\mathrm{D}=7528>]$.

HEYWOOD, A. (1997): Politics, Londres, Macmillan.

HIRST, P.; y THOMPSON, G. (1996): Globalization in Question, Cambridge, Polity Press.

JENSON, J. (2007): Redesigning Citizenship Regimes after Neoliberalism. Ideas about Social Investment, Montreal, Canada Research Chair in Citizenship and Governance [rhttp://www.cccg.umontreal. ca/pdf/Jenson\%20RC19\%2007.pdf〉].

JENSON, J.; y SAINT-MARTIN, D. (2006): "Building blocks for a new social architectures: The LEGOTM paradigm of an active society", Policy \& Politics, vol. 34, n- 3 , págs. 429-451.

JESSOP, R. (2008): El futuro del Estado capitalista, Madrid, Los Libros de la Catarata.

MARSHALL, T. H.; y BOTTOMORE, T. (1998): Ciudadanía y clase social, Madrid, Alianza.

MERKEL, W. (2001): “La tercera vía de la socialdemocracia europea a finales del siglo XX”, La Política, vol.5, págs. 7-44.

- (1994): "Introducción: los desafíos de la socialdemocracia a finales del siglo XX", en MERKEL, W. (ed.): Entre la modernidad y el postmaterialismo. La socialdemocracia europea a finales del siglo XX, col. Universidad, Madrid, Alianza, págs. 9-26.
MISHRA, R. (1996): “The welfare of nations", en BOYER, R.; y DRACHE, D. (eds.), States against Markets. The Limits of Globalization, Londres, Routledge, págs. 316-333.

- (1992): El Estado de bienestar en crisis, Madrid, Ministerio de Trabajo y Seguridad Social.

MOREL, N.; PALIER, B.; y PALME, J. (2012): "Beyond the welfare state as we knew it?", en MOREL, N. PALIER, B.; y PALME, J. (eds.), Towards a Social Investment Welfare State, Bristol, Polity Press, págs. 1-30.

PFALLER, A.; GOUGH, I.; y THERBORN, G. (1993), Competitividad económica y Estado de bienestar. Estudio comparativo de cinco países avanzados, Madrid, Ministerio de Trabajo y Seguridad Social.

PICÓ, J. (1992): Los límites de la socialdemocracia europea, Madrid, Siglo XXI.

PIERSON, C. (1998a): "Contemporary challenges to welfare state development”, Political Studies, vol. 46, no 4 , págs. 777-794.

- (1998b): "Irresistible forces, immovable objects: Postindustrial welfare states confront permanent austerity", Journal of European Public Policy, vol. 5, nํ 4, págs. 539-560.

PLANT, R. (2004): "Neo-liberalism and the theory of the state: From Wohlfahrtsstaat to Rechtsstaat", en GAMBLE, A.; y WRIGHT, T. (eds.), Restating the State?, Oxford, Blackwell, págs. 24-37.

PROCACCI, G. (2001): "Poor citizens: social citizenship versus individualization of welfare", en CROUCH, C.; EDER, K.; y TAMBINI, D. (eds.), Citizenship, Markets and the State, Oxford, Oxford University Press, págs. 49-68.

SWANK, D. (2001): "Political institutions and welfare state restructuring. The impact of institutions on social policy change in developed democracies", en PIERSON, P. (ed.), The New Politics of the Welfare State, Oxford, Oxford University Press, págs. 197-237.

TAYLOR-GOOBY, P. (2004): "New risks and social change", en TAYLOR-GOOBY, P. (ed.), New Risks, New Welfare. The Transformation of the European Welfare State, Oxford, Oxford University Press.

TORFING, J. (1999): "Workfare with welfare: Recent reforms of the Danish welfare state", Journal of European Social Policy, vol. 9, noำ 1, págs. 5-28.

VALLESPÍN, F. (2000): El futuro de la política, col. Pensamiento, Madrid, Taurus.

VANDENBROUCKE, F.; HEMERIJCK, A.; y PALIER, B. (2011): "The EU needs a social investment pact", Observatoire Social Européen Paper Series, nํ 5 [<http://www.ose.be/files/OpinionPaper5_ Vandenbroucke-Hemerijk-Palier_2011.pdf〉].

VV.AA. (1993): La larga noche neoliberal, Madrid, Icaria.

YEATES, N. (2001): Globalization \& Social Policy, Londres, Sage Publications. 